\title{
FURTHER EVIDENCE OF GASEOUS EMBOLIC MATERIAL IN PATIENTS WITH ARTIFICIAL HEART VALVES
}

\author{
D. Georgiadis, MD \\ R. W. Baumgartner, $\mathrm{MD}^{\mathrm{b}}$ \\ R. Karatschai, $\mathrm{MD}^{\mathrm{a}}$ \\ A. Lindner, $\mathrm{MD}^{\mathrm{a}}$ \\ H. R. Zerkowski, $\mathrm{MD}^{\mathrm{c}}$
}

\begin{abstract}
Objective: We undertook this study to evaluate the hypothesis that most microemboli signals in patients with artificial heart valves are gaseous, assuming that microemboli counts in cerebral arteries would progressively decline with increasing distance from the generating heart valve. Methods: A total of 10 outpatients with CarboMedics (Sulzer Carbomedics Inc., $n=$ $5)$ and ATS prosthetic heart valves $(n=5)$ in the aortic $(n=8)$, mitral $(n=$ 1), or both aortic and mitral positions $(n=1)$ were recruited. Monitoring was performed simultaneously over the middle and anterior cerebral arteries and the common carotid artery for 30 minutes with the 2 MHZ transducers of a color duplex scanner (common carotid artery) and pulsed-wave Doppler ultrasonography (intracranial arteries). All data were harvested in an eight-channel digital audio tape recorder, and microembolic signal counts were evaluated online by two separate observers. Results: Significantly higher microembolic signal counts were recorded in the common carotid artery (112 [75 to 175]) compared with the middle and anterior cerebral arteries (30 [18 to 36], $p<0.0001)$. Interobserver variability was satisfactory $(k=0.81)$. Conclusions: Our results strongly argue for gaseous underlying embolic material in patients with artificial heart valves because bubbles are bound to implode with time. (J Thorac Cardiovasc Surg 1998;115:808-10)
\end{abstract}

S everal reports described a high prevalence of Doppler microembolic signals (MES) in patients with artificial heart valves. ${ }^{1-4}$ The underlying material of these signals, however, has not yet been defined. Although recent observations argue for gaseous emboli, ${ }^{5-8}$ equivocal proof is currently not available. Because the life span of air bubbles is limited, their counts would progressively decline with increasing distance from the generating heart valve. This condition would obviously not be fulfilled by formed particles. Simultaneous ultrasound monitoring of the common carotid (CCA) and the

From the Departments of Neurology a and of Cardiothoracic Surgery, ${ }^{\mathrm{c}}$ University of Halle, Halle, Germany, and the Department of Neurology, ${ }^{\mathrm{b}}$ University of Zürich, Zürich, Switzerland.

Supported by an unrestricted research grant of Cobe Cardiovascular Inc., Denver, Colo.

Received for publication Sept. 26, 1997; accepted for publication Oct. 7, 1997.

Address for reprints: D. Georgiadis, MD, Department of Neurology, University of Halle, Ernst-Grube-Str 40, Halle 06122, Germany.

Copyright (C) 1998 by Mosby, Inc.

$0022-5223 / 98 \$ 5.00+0 \quad \mathbf{1 2 / 1 / 8 6 7 1 8}$ ipsilateral middle (MCA) and anterior (ACA) cerebral arteries in patients with artificial heart valves could thus provide conclusive evidence on the nature of the embolic material.

\section{Patients and methods}

Ten patients with artificial heart valves, eight men and two women, aged $38 \pm 6$ years (mean $\pm S D$, minimum 16 , maximum 65 years) were enrolled in this study after informed consent. Normal color duplex and pulsed-wave Doppler sonography findings of the extracranial and intracranial cerebral arteries and willingness to attend served as inclusion criteria. ATS (ATS, Lanarkshire, Scotland, $n=5$ ) and CarboMedics (Sulzer Carbomedics Inc., $n=5)$ valves were inserted in the aortic $(n=8)$, mitral $(n=1)$, or both aortic and mitral $(n=1)$ positions $18 \pm 2$ months before the transcranial Doppler examination. Transcranial Doppler monitoring over the ACA and MCA was performed with the $2 \mathrm{MHZ}$ probes of a pulsed Doppler machine (Multi-Dop X-4, DWL, Germany), whereas the CCA was monitored with a $2 \mathrm{MHZ}$ sector scan (Acuson XP 4, Acuson, Inc., Mountain View, Calif.) With a spatial peak time average intensity $<50 \mathrm{~mW} / \mathrm{cm}^{2}$, a sample volume ranging between 2 and $3 \mathrm{~mm}$, and a 128-point fast Fourier transform (FFT). Monitoring of the common instead of the internal carotid artery in the caudal direction was mandatory to prevent acoustic interference between the two Doppler transducers. Monitoring 
depths were 60 to $64 \mathrm{~mm}, 50$ to $56 \mathrm{~mm}$, and 16 to $26 \mathrm{~mm}$ for the ACA, MCA, and CCA, respectively. CCA monitoring was performed with a hand-held transducer, whereas an elastic frame was used for transcranial monitoring. MES were detected online, on the basis of recently published criteria, ${ }^{9}$ with the exception that no decibel threshold was applied to MES detected in the CCA because their intensity could not be quantified. All data were recorded on an eight-channel digital audio tape recorder (TASCAM DA 88), and reviewed off-line by an examiner independent to those performing ultrasound monitoring and blinded to both their results and the patients' identity. Only signals recognized as such by all observers involved were included in the final evaluation. MES counts in the ACA were added to those in the MCA, and the total count was used for further evaluation.

Non-normally distributed data were expressed as median, $95 \%$ confidence intervals $(95 \% \mathrm{CI})$, and compared using the Mann-Whitney U test. Cohens' kappa was used to assess specific agreement between the observers. Acquired values indicate acceptable agreement if they are between 0.4 and 0.75 and excellent agreement if they are $>0.75(p<0.0001$, Mann-Whitney, individual values listed in Table I). ${ }^{10}$

\section{Results}

Significantly higher MES counts were evident in the CCA compared with the MCA/ACA (112 [75 to 175 ] vs 30 [18 to 36], median and $95 \% \mathrm{CI}, p<$ 0.0001 , Mann-Whitney). Observer agreement was satisfactory $(\kappa=0.78$ for CCA and $\kappa=0.81$ for MCA/ACA)

\section{Discussion}

This is the first report of simultaneous transcranial Doppler monitoring over the CCA, MCA, and ACA in patients with artificial heart valves. The basic limitation of this study was the fact that the CCA, instead of the internal carotid artery, was monitored. Thus it is possible that a portion of the MES detected in the CCA subsequently followed the external carotid artery. Still, this could at most be true for $10 \%$ to $20 \%$ of emboli and could not be the sole explanation for our observation. In addition, because two ultrasound devices were used, it appears possible that their sensitivity in MES detection was different. Still, the frequency of both transducers was identical, minimizing discrepancies in sensitivity.

The observed decline of MES counts between the CCA and the MCA/ACA could be due to implosion of bubbles with growing distance from their place of origin, assuming gaseous embolic material, although no plausible explanation can be provided, assuming that the underlying material is formed. Several previous observations in patients with artificial heart
Table I. Microembolic signal counts in the monitored vessels in 10 patients with prosthetic cardiac valves

\begin{tabular}{lrc}
\hline \multicolumn{1}{c}{ Valve type, position } & $C C A$ & $M C A / A C A$ \\
\hline 1. CM, AVR+MVR & 165 & 32 \\
2. CM, AVR & 72 & 32 \\
3. ATS, AVR & 52 & 10 \\
4. CM, AVR & 106 & 34 \\
5. ATS, AVR & 77 & 10 \\
6. CM, MVR & 67 & 4 \\
7. ATS, AVR & 284 & 27 \\
8. ATS, AVR & 135 & 36 \\
9. ATS, MVR & 152 & 61 \\
10. CM, AVR & 115 & 27 \\
\hline
\end{tabular}

$A V R$, Aortic; $M V R$, mitral; $A V R+M V R$, aortic and mitral valve replacement; $C C A$, common carotid artery; $M C A$, middle cerebral artery; $A C A$, anterior cerebral artery. All microembolic signal counts expressed as microembolic signals per hour.

valves, including the lacking ${ }^{4}$ or marginal ${ }^{2,3}$ clinical or hematologic ${ }^{11}$ correlations of MES, the significant influence of oxygen inhalation on their counts, ${ }^{6,7}$ and their characteristics on multifrequency monitoring, ${ }^{8}$ also argue for gaseous material. Still, the generating mechanism of gas bubbles remains unclear. Cavitation caused by blood acceleration and deceleration through valve opening and closure provides a potential explanation, but cavitation bubbles are reported to implode within milliseconds and could not therefore enter the cerebral circulation. $^{12}$

In summary, we observed significantly higher MES counts in the CCA compared with the MCA/ ACA, which most probably argues for gaseous embolic material.

\section{REFERENCES}

1. Rams JJ, Davis AD, Lolley MD, Berger PM, Spencer MP. Detection of microemboli in patients with artificial heart valves using transcranial Doppler: preliminary observations. J Heart Valve Dis 1993;2:37-41.

2. Braekken KS, Russell D, Brucher R, Svennevig J. Incidence and frequency of cerebral embolic signals in patients with a similar bileaflet mechanical heart valve. Stroke 1995;26:1225-30.

3. Sliwka U, Diehl RR, Meyer B, Schönhube F, Noth J. Transcranial Doppler 'high-intensity transient signals' in the acute phase and long-term follow-up of mechanical heart valve implantation. J Stroke Cerebrovasc Dis 1995;5:139-46.

4. Georgiadis D, Grosset DG, Kelman AW, Faichney A, Lees $\mathrm{KR}$. Incidence and characteristics of intracranial microemboli signals in patients with different types of prosthetic cardiac valves. Stroke 1994;25:587-92.

5. Spencer MP. Hyperbaric compression and Doppler-detected microemboli in prosthetic valve patients [abstract]. Cerebrovasc Dis 1996;6(suppl 3):69.

6. Kaps M, Hansen J, Weiher M, Tiffert K, Kayser I, Droste 
DW. Clinically silent microemboli in patients with artificial prosthetic aortic valves are predominantly gaseous and not solid. Stroke 1997;28:322-6.

7. Georgiadis D, Wenzel A, Lehmann D, Lindner A, Zierz S, Spencer MP. Influence of oxygen inhalation on Doppler microemboli signals in patients with artificial heart valves. Stroke 1997;28:2189-94.

8. Russel D, Brucher R. Discrimination between solid and gaseous cerebral microemboli using multifrequency Doppler. J Neuroimaging 1997; 7:230.

9. Consensus Committee of the Ninth International Cerebral
Hemodynamics Symposium. Basic identification criteria of Doppler microembolic signals. Stroke 1995;26:1123.

10. Fleiss JL. Statistical methods for rates and proportions. In: Statistical methods and proportions. 2nd ed. New York: John Wiley; 1981. p. 212-25.

11. Georgiadis D, Mallinson A, Grosset DG, Lees KR. Emboli signals and coagulation activity in patients with prosthetic heart valves. Stroke 1994;25:1211-4.

12. Graf T, Fischer H, Reul H, Rau G. Cavitation potential of mechanical heart valve prostheses. Int J Artif Organs 1991; $14: 169-74$.

Don't miss a single issue of the journal! To ensure prompt service when you change your address, please photocopy and complete the form below.

Please send your change of address notification at least six weeks before your move to ensure continued service. We regret we cannot guarantee replacement of issues missed due to late notification.

\section{JOURNAL TITLE:}

Fill in the title of the journal here.

OLD ADDRESS:

Affix the address label from a recent issue of the journal here.
NEW ADDRESS:

Clearly print your new address here.

Name

Address

City/State/ZIP
COPY AND MAIL THIS FORM TO:

Periodical Subscription Services

Mosby, Inc.

11830 Westline Industrial Dr.

St. Louis, MO 63146-3318
OR FAX TO:

314-432-1158

N/Mosby
OR PHONE:

1-800-453-4351

Outside the U.S., call

314-453-4351 